South African Journal of Geomatics, Vol. 4, No. 4, November 2015

\title{
Determination of Urban Thermal Characteristics on an Urban/Rural Land Cover Gradient Using Remotely Sensed Data
}

\author{
Sithole, K, Odindi, J. O.* \\ School of Agricultural, Earth and Environmental Sciences, University of KwaZulu-Natal, \\ Pietermaritzburg, South Africa, Odindi@ukzn.ac.za
}

DOI: http://dx.doi.org/10.4314/sajg.v4i4.3

\begin{abstract}
The transformation from natural to impervious surfaces in an urbanization process and the urban heat island (UHI) phenomenon is known to significantly compromise urban environmental quality and has been linked to climate change and associated impacts. Whereas the existence of UHI is common knowledge, the implication of urban land use land cover (LULC) gradient on intra-urban thermal characteristics is often poorly understood. A recent proliferation of remotely sensed datasets offer great potential in understanding the relationship between urban LULCs and their respective thermal characteristics, a critical basis for urban environmental management and designing climate change mitigation measures. This study explores the potential of multispectral remotely sensed dataset in determining the influence of rural/urban LULC gradient on urban thermal characteristics. A rectangular eleven band Landsat 8 image subset was delineated from the central business district to the rural periphery and classified into most dominant LULCs and a corresponding Landsat 8 thermal layer used to determine the LULCs thermal characteristics. Digitized point data was used to determine differences in land surface temperature (LST) over gradient's LULC types. Results showed that there was varied contribution of LULCs to the LST. As expected, the density of built up surfaces and LST decreased towards the city's periphery while a decline in vegetation density from the periphery led to an increase in LST. These results provide valuable insights into the value of remotely sensed datasets in understanding the implication of intra-urban LULC gradient on LST characteristics. Specifically, the study demonstrates the value of remotely sensed data as aids to sustainable urban environmental planning.
\end{abstract}




\section{Introduction}

Urbanization has been identified as a major influence to the transformation of land use and land covers (LULCs) and a key driver to environmental change (Kardinal et al., 2007; Xuejie et al., 2003). Typically, this transformations involve conversion of natural landscapes like wetlands, rivers, forests, grasslands and unused lands into built-up areas like tarred roads, concrete pavements and buildings (Buyadi et al., 2013; Deosthali, 2000; Radhi et al., 2013). According to Qian et al. (2006) and Oke (1987), such transformations are known to influence local, regional and even global climate.

In urban landscapes, remnant natural landscapes and converted impervious LULC mosaics act as thermal sources and sinks respectively (Weng, 2001). Commonly, these mosaics influence urban Land Surface Temperature (LST) as they determine a surfaces' solar radiation and absorption, thermal capacity and heat conductivity (Qian et al., 2006). On a larger scale, the elevated urban LST is often distinct from the cooler peripheral and rural landscapes, a phenomenon referred to as the Urban Heat Island (UHI). This phenomenon is known to significantly affect micro and macro climate, deteriorate urban environment and has been identified as a major influence to climate change and associated impacts (Timmerman and White, 1997). Whereas urban/rural thermal variability is now common knowledge, influence of urban LULCs gradient, which form the basis for the UHI, is often poorly understood. This can be attributed to, until recently, lack of appropriate integrative techniques that could be used to effectively determine the influence of urban LULCs on their respective thermal characteristics. Recently, remote sensing techniques and datasets have become valuable for spatial data acquisition, integration and analysis for environmental decision making (Mirzaei and Haghighat, 2010; Streutker, 2002). According to Lillesand and Kiefer (2000) and Mirzaei and Haghighat (2010), a significant advantage of using remote sensing datasets and techniques is the ability to identify, standardize and improve data quality and to accurately derive required information. In concert with Geographic Information System (GIS), remote sensing provide unparalleled analytical abilities for assessing spatial environmental characteristics valuable in urban environmental planning, decision making and as aids to designing necessary mitigation measures. In this study, using remotely sensed datasets and GIS techniques, we seek to determine the influence of urban/rural LULC gradient on thermal characteristics around the city of Pietermaritzburg. 


\section{Data and methods}

The study was conducted in the city of Pietermaritzburg, Umgungundlovu District, KwaZuluNatal province of South Africa (Figure 1). To determine the LULC thermal variability, a digital urban/rural rectangular transect measuring 30 x $5 \mathrm{~km}$ was generated from the central business district (CBD) of Pietermaritzburg city towards the north westerly periphery (Figure 1). To minimise the influence of altitude on thermal variability, and to ensure representative transition to the periphery, the transect was selected based on least change in altitude and gradually changing LULCs.

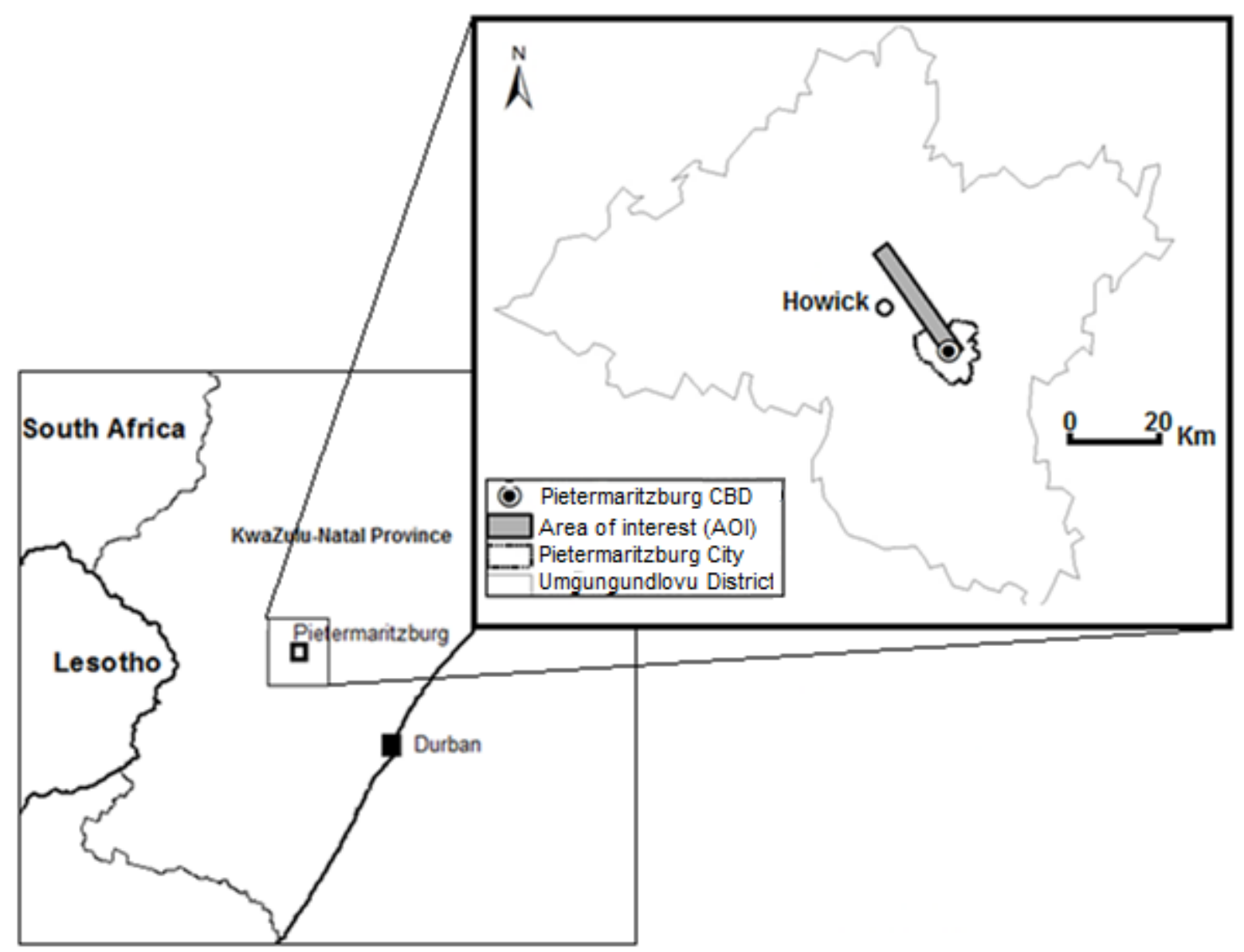

Figure 1: The general study area and Area of Interest (AOI).

A cloud-free Landsat 8 Operational Land Imager (OLI) Level 1T (radiometric, geometric and terrain corrected image) row 80, path168 image captured on 23 March 2014 at 07:51 GMT was acquired for the study. Since the image is delivered pre-processed, no further pre-processing was required. All the scene's bands were stacked and a rectangular area of interest (AOI) subset from the study area generated. An un-supervised classification was first used to gain an insight into the 
existing LULC types within the study area. A supervised classification scheme, using maximum likelihood algorithm, was then used to amalgamate the major LULC covers. Six major LULC classes within the AOI were identified - High density built up, Low density built up, High density vegetation, Low density vegetation, Water and Very low/no vegetation (Table 1).

Table 1: Land features included in land use/land cover (LULC) classes.

\begin{tabular}{ll}
\hline LULC & Amalgamated LULC name \\
\hline $\begin{array}{l}\text { Industrial sites, sky rise buildings, central } \\
\text { business district } \\
\text { Single-storey residential area, homesteads }\end{array}$ & High density built up \\
Forests, thick thickets & Low density built up \\
Cropland, grassland & High density vegetation \\
Rivers, dams, lakes, ponds & Low density vegetation \\
Bare land, sand & Water \\
\hline
\end{tabular}

To validate the LULCs, 256 stratified random points were generated from an associated aerial photograph and the image's higher spatial resolution panchromatic band. The points were then used to generate an error matrix and overall, user's and producer's accuracies and Kappa statistic generated.

The OLI spectral band 10 was used to derive the LST for the LULC gradient. Equations 1 and 2 were then used to convert the Landsat 8 Digital Numbers (DN) to LST. Equation 1 was used to convert Digital Numbers (DN) to spectral radiance while equation 2 was used to convert spectral radiance to brightness temperature.

$$
\mathrm{L} \lambda=\mathrm{MLQcal}+\mathrm{AL}
$$

Where: $\mathrm{L} \lambda$ is the spectral radiance (Watts/ $(\mathrm{m} 2 * \operatorname{srad} * \mu \mathrm{m}), \mathrm{ML}$ is the band specific multiplicative rescaling factor from the metadata (RADIANCE_MULT_BAND_10), Qcal is quantized calibrated standard product pixel values (DN) and AL is band specific additive rescaling factor from the metadata. 


$$
T=\frac{K_{2}}{\ln \left(\frac{K_{1}}{L_{\lambda}}+1\right)}
$$

Where: $\mathrm{T}$ is at satellite brightness temperature in Kelvin $(\mathrm{K}), \mathrm{L} \lambda$ is spectral radiance (Watts/(m2* $\left.\operatorname{srad}^{*} \mu \mathrm{m}\right), \mathrm{K} 1$ is band-specific thermal conversion constant from metadata (K1_CONSTANT_BAND_10) and K2 is band-specific thermal conversion constant from the metadata (K2_CONSTANT_BAND_10).

The brightness temperature was converted from Kelvin (K) to Degrees Celcius (C) using Equation 3.

$$
{ }^{\circ} \mathrm{C}=\mathrm{K}-273
$$

Where: $\mathrm{C}$ is the temperature in Degrees Celsius and $\mathrm{K}$ is the temperature in Kelvin.

To determine the influence of LULCs on the urban/rural variability, the classified LULC layer was vectorised into a polygon layer and a union function used to generate six polygons in the attributes table. Within each of the six LULC classes, 200 random points (with $30 \mathrm{~m}$ minimum distance) were generated (Figure 2). The respective LULC random points were then used to extract LST values from the thermal layer. These values were added to output attribute table LULC class field and used for analysis. 

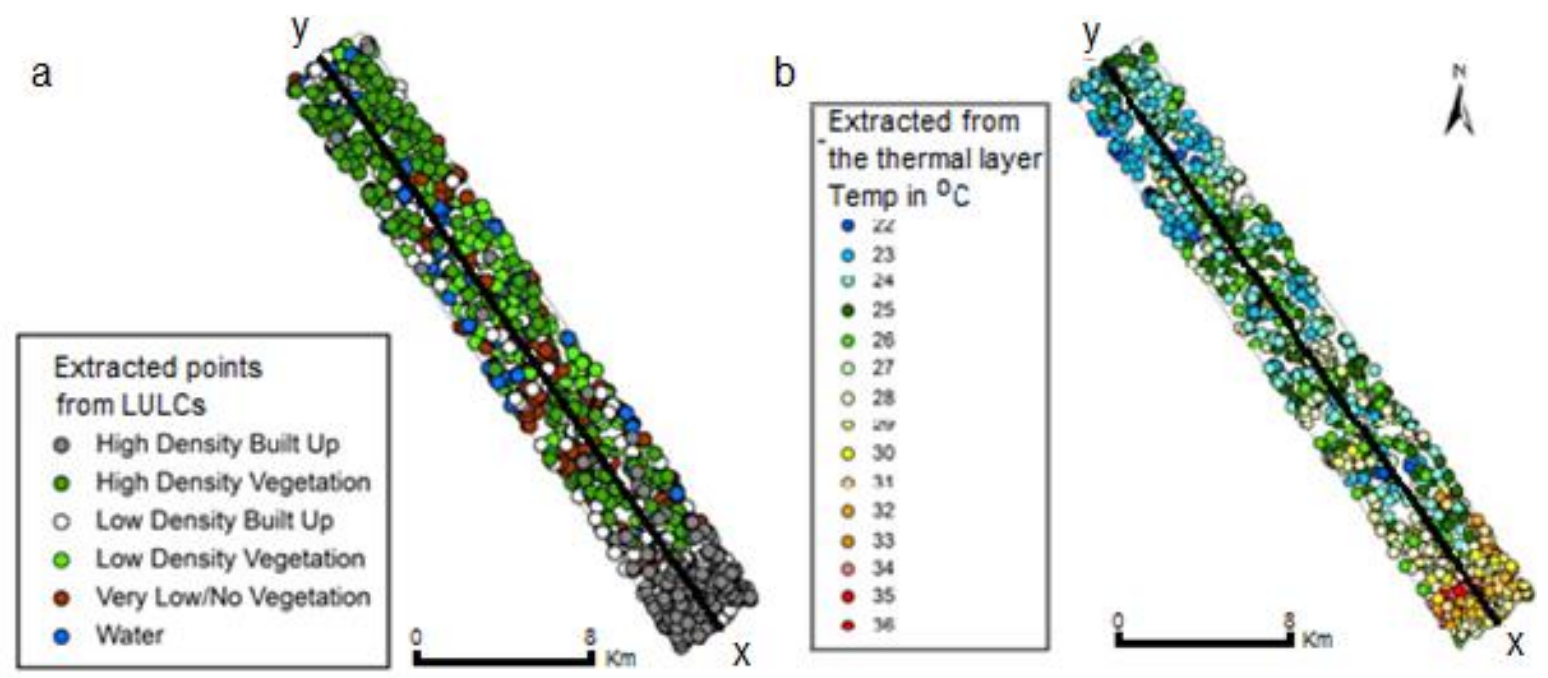

Figure 2: Points representing the distribution of land use land covers within the Area of Interest (a) and respective thermal variability (b). The points have been exaggerated to show land use land cover variability and respective thermal values respectively. Central Business District (x) natural peripheral boundary (y).

The overall urban/rural thermal variability from the urban core to the natural peripheral landscape was determined using sixty two points digitized along a straight line at approximately $50 \mathrm{~m}$ intervals on the classified LULC layer (Refer to figure $2 \mathrm{a}$ and $\mathrm{b}$ ).

\section{Results and discussion}

Recent insights into urban heat island (UHI) and its implication on climate change has increased the need for an understanding of the influence of urbanisation transformation on urban thermal characteristics (Kardinal et al., 2007; Radhi et al., 2013; Weng, 2001; Zhang and Huang, 2012). However, to date, the efficacy traditional techniques like surveys and in situ meteorological data have been impeded by among others lack of integrative and comparative capabilities at relevant spatial resolutions. Due to their relatively lower cost in addition to the above named limitations, remotely sensed datasets have recently become valuable in understanding the relationship of urban LULCs and their respective thermal characteristics (Senanayake et al., 2013; Takeuchi et al., 2010; Xiao-Ling Chen, 2006).

Using the Maximum Likelihood classification scheme, this study identified six major LULCs types. Figure 3 shows the classified land use land covers (a) and associated surface temperatures (b). High density built up areas were mainly concentrated at the southern end of the study area, 
with the Low density built ups surrounding the High density built up areas, diffusing outwards. There was a general increase in natural LULC (High and Low dense vegetation and Water) towards the study area's periphery. The city of Pietermaritzburg is characterised by High density built up region that also forms the core zone of economic activity (Central Business District). The city is also characterised by Low density built up areas around the CBD and an outward gradual increase in areas with vegetation and vegetative biomass per unit area. This finding is consistent with the general concept urban transformation on natural landcapes characterised by gradual transition from urban built up areas like tarred roads, concrete pavements and buildings to natural and greenery landscape like wetlands, rivers, forests, grasslands and unused lands (Buyadi et al., 2013; Deosthali, 2000; Radhi et al., 2013; Takeuchi et al., 2010; Weng 2001).
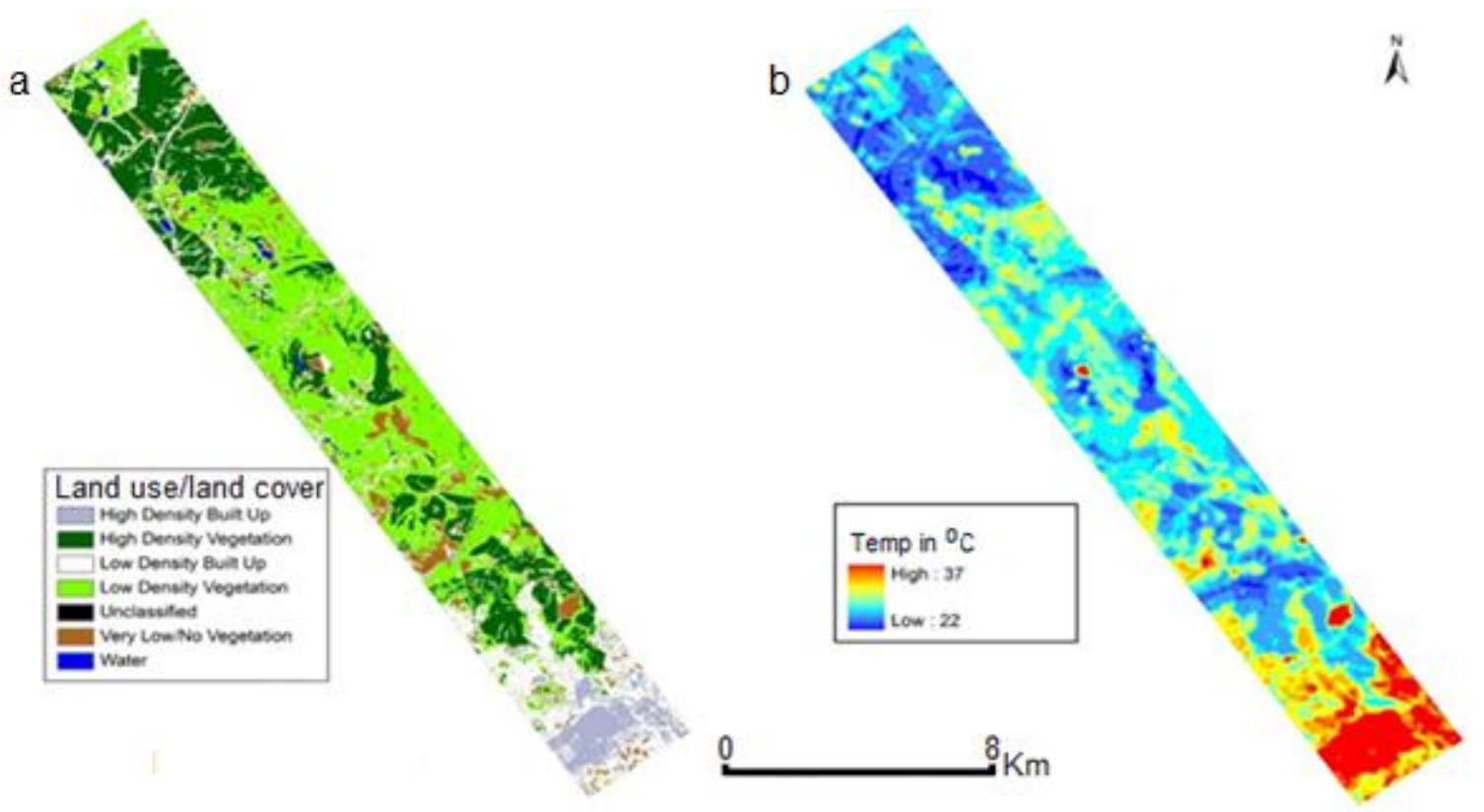

Figure 3: Land use/land cover types over study area (a) and land surface temperature over study area (b).

Results in this study show the potential of remotely sensed data in relating urban LULCs to respective thermal characteristics. The success of the Landsat8 used in this study can be attributed to its relatively higher spatial resolution $(30 \mathrm{~m})$, which allows for adequate detection of finer differences in urban LULC types. In this study, there was a $73.85 \%$ overall classification accuracy and 0.67 overall kappa statistics (Table 2), which was above the minimum (70\%) threshold recommended by Takeuchi et al. (2010) and Weng (2001). However, the classification accuracy 
differed widely between LULC groups. The user's accuracy of High density built up for instance was lower (46.43\%) compared to the other LULC types. This can be attributed to a wide range of features within the built up landscape, reducing the separability of spectral signatures from other LULC types. Conversely, due to high surface homogeneity, High Density Vegetation had a higher user's accuracy (89.47\%). The uniformity of the surface of Very Low/No Vegetation and clear distinction from other LULC types account for the highest producer's accuracy of $94.44 \%$.

Table 2: Accuracy Assessment - Error matrix (Totals).

\begin{tabular}{lccccc}
\hline Class Name & $\begin{array}{c}\text { Reference } \\
\text { Totals }\end{array}$ & $\begin{array}{c}\text { Classified } \\
\text { Totals }\end{array}$ & $\begin{array}{c}\text { Number } \\
\text { Correct }\end{array}$ & $\begin{array}{c}\text { Producer's } \\
\text { Accuracy (\%) }\end{array}$ & $\begin{array}{l}\text { User's } \\
\text { Accuracy (\%) }\end{array}$ \\
\hline High Density Built Up & 15 & 28 & 13 & 86.67 & 46.43 \\
High Density Vegetation & 67 & 57 & 51 & 76.12 & 89.47 \\
Low Density Built Up & 49 & 51 & 31 & 63.27 & 60.78 \\
Low Density Vegetation & 86 & 75 & 63 & 73.26 & 84.00 \\
Very Low/No Vegetation & 18 & 29 & 17 & 94.44 & 58.62 \\
Water & 25 & 20 & 17 & 68.00 & 85.00 \\
Totals & 260 & 260 & 192 & & \\
Overall Classification Accuracy $=73.85 \%$ & & & \\
Overall Kappa Statistics $=0.67$
\end{tabular}

There were clear LST variations over the study area (refer to Figure 3b above). Generally, higher LST values (High density built up) were in lower end of the study area and lower LST (High and low density vegetation) were found in the upper end of the study area (Figure 3). Generally, there was a clear relationship between built-up density and thermal intensity (Figure 3 and 4). 


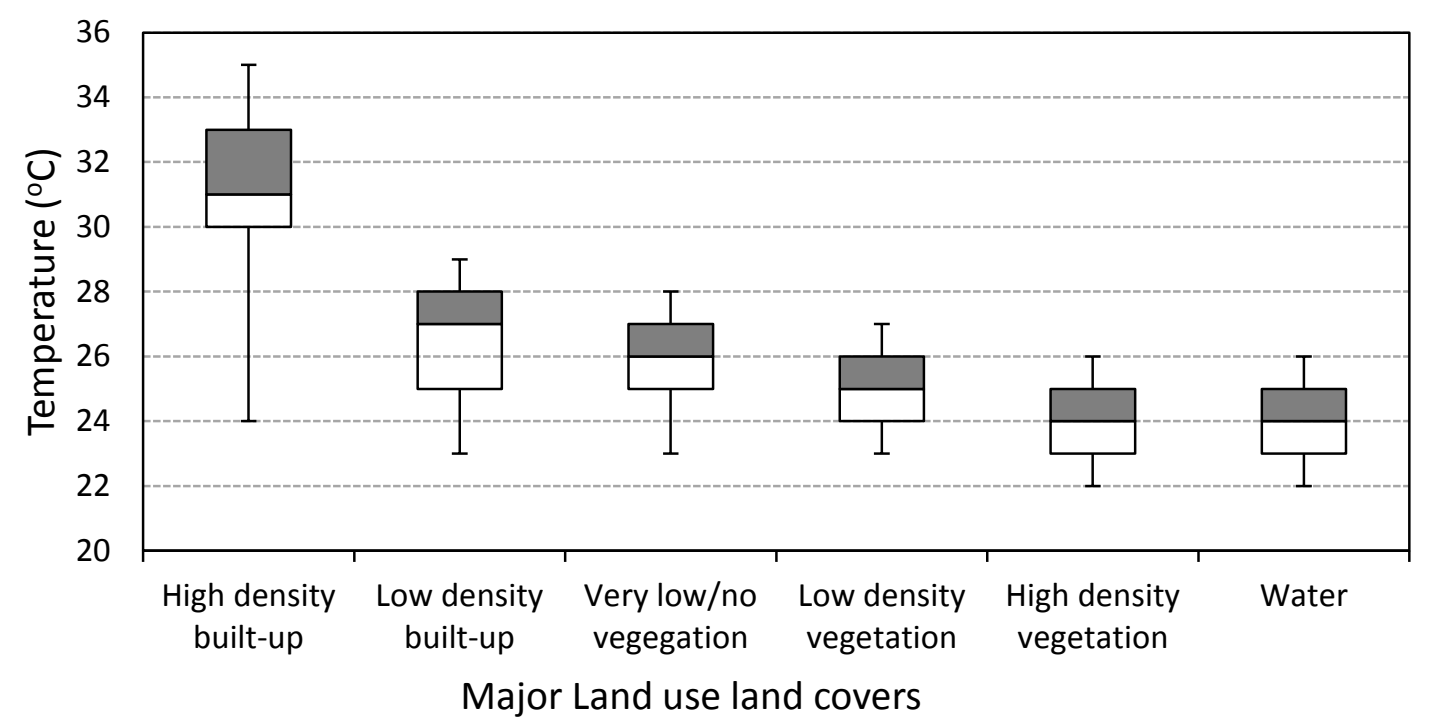

Figure 4: Land surface temperature above different LULCs extending from the Pietermaritzburg Central Business.

Based on an urban/rural transect (refer to Figure 2), there was a clear decline in temperature from the CBD to the periphery (Figure 5). There was a general decrease in thermal values from the High density built up, Low density built up, Low density/no vegetation to High density vegetation respectively (Figure 5). In consistency with Deosthali (2000) and Dousset and Gourmelon (2003), the highest LST was at the CBD, characterised by built impervious surfaces and therefore low albedo (Qian et al., 2006; Sobrino et al., 2004; Weng, 2001). According to Jin et al. (2005), such built up areas absorb high amounts of electromagnetic radiation and releases high amounts of heat energy and therefore a major thermal source within an urban landscape. The lowest LST was found at high density vegetation and water bodies. These green spaces act as heat sinks, as they tend to be porous and assimilate local heat. Such porous surfaces absorb heat energy from the atmosphere to percolate, which reduce the LULCs respective LST. Generally, green spaces are characterised by higher albedo than built up areas, therefore, LST tends to decrease as you move from the urban CBD to the rural periphery (Senanayake et al., 2013; Streutker, 2002; Takeuchi et al., 2010; Xuejie et al., 2003). 


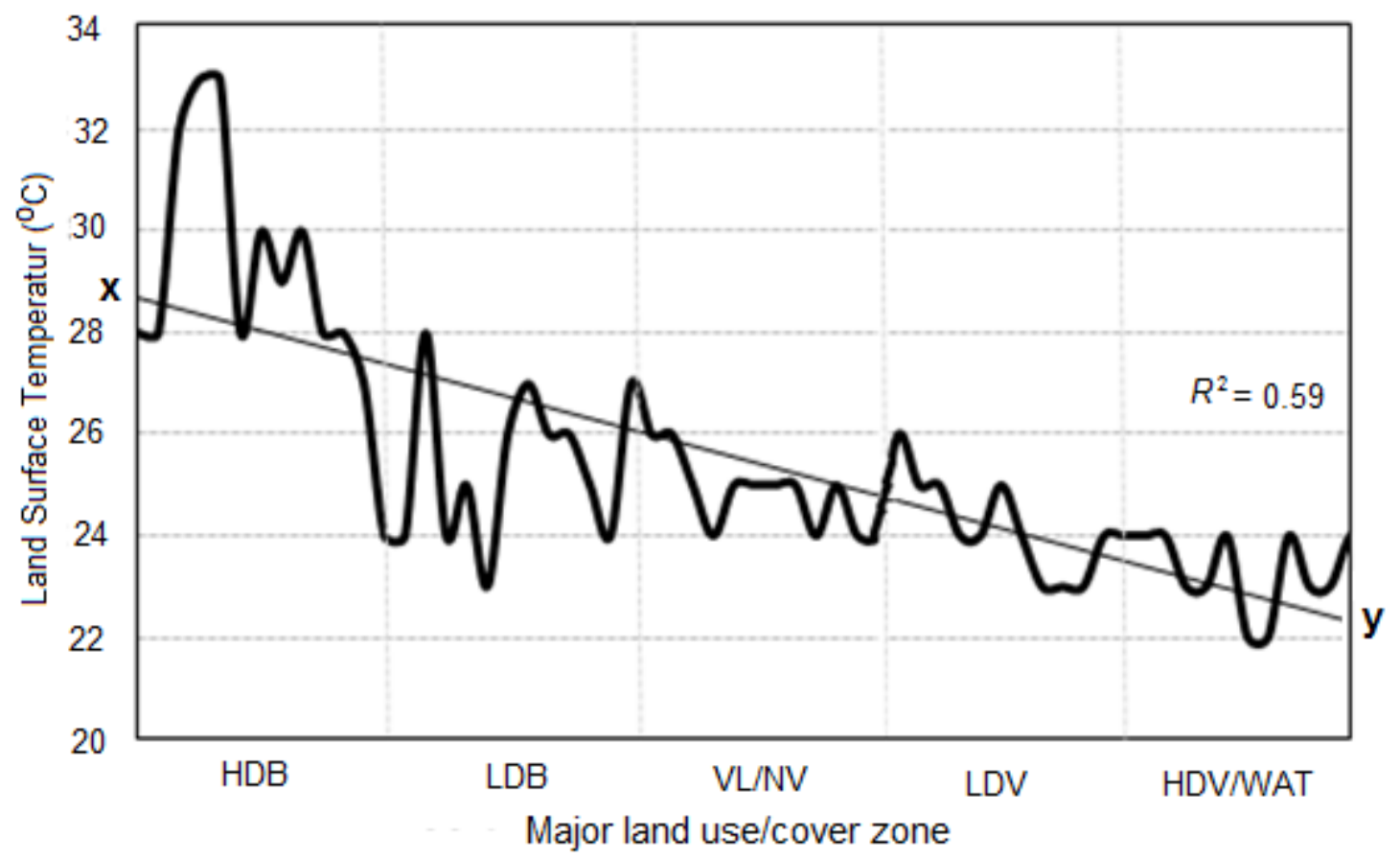

Figure 5:Land surface temperature profile across different land use/land cover regions, with regression line. (High density built up - HDB; Low density built up - LDB; Very low/no vegetation VL/NV; Low density vegetation - LDV; High density vegetation and Water - HDV and WAT). Central Business District (x) to the natural peripheral boundary (y).

Results in this study demonstrate the potential of remotely sensed dataset in understanding the implication of urban LULC transformation on urban thermal characteristics. Specifically, these results demonstrate the potential for quantification of urban LULCs vis-à-vis urban thermal characteristics, valuable for designing and implementation of urban environmental management plans. Techniques and datasets used in this study are particularly valuable in urban environmental management, including mitigation of climate change and associated impacts.

\section{Conclusions}

This study used Landsat8 imagery to determine the distribution of major LULC types, temperature variability, and the influence of LULC change on LULC on Pietermaritzburg's LST. The following conclusions were drawn:

- Multispectral data from Landsat8 sensor has a great potential for studying the variability in LST over urban LULC change. 
- Using the maximum likelihood algorithm, an overall classification accuracy of $73.85 \%$ was obtained, demonstrating the reliability of the algorithm on the multispectral remotely sensed Landsat 8 for urban LULC classification.

- From the central urban areas to the rural periphery, the density of built up surfaces decreased while the density of vegetation surfaces increased.

- Land surface temperature decreased from the central urban areas to the rural periphery.

- Generally, LST values decreased from built-up urban core to the natural landscape at the periphery. 


\section{References}

Buyadi, SNA, Mohd, WMNW \& Misni, A 2013 'Impact of land use changes on the surface temperature distribution of area surrounding the national botanic garden, Shah Alam', Procedia - Social and Behavioral Sciences, vol. 101, pp. 516-525.

Deosthali, V 2000 'Impact of rapid urban growth on heat and moisture islands in pune city, india', Atmospheric Environment, vol 34, pp. 2745-2754.

Dousset, B \& Gourmelon, F 2003 'Satellite multi-sensor data analysis of urban surface temperatures and landcover', ISPRS Journal of Photogrammetry and Remote Sensing, vol. 58, pp. 43-54.

Jin, M, Dickinson, RE \& Zhang, D 2005 'The footprint of urban areas on global climate as characterized by modis', Journal of Climate, vol. 18, pp. 1551-1565.

Kardinal, JS, Wong, NH, Hagen, E, Anggoro, R \& Hong, Y 2007 'The influence of land use on the urban heat island in singapore', Habitat International, vol. 31, pp. 232-242.

Lillesand, TM \& Kiefer, RW 2000 'Remote sensing and image interpretation', John Wiley \& Sons New Jersey.

Mirzaei, PA \& Haghighat, F 2010 'Approaches to study urban heat island-abilities and limitations', Building and Environment, vol. 45, pp. 2192-2201.

Oke, TR 1987, Boundary layer climates. Psychology Press, Vancouver.

Qian, LX, Cui, H \& Chang, J 2006 'Impacts of land use and cover change on land surface temperature in the zhujiang delta', Pedosphere, vol. 16, pp. 681-689.

Radhi, H, Fikry, F \& Sharples, S 2013 'Impacts of urbanisation on the thermal behaviour of new built up environments: A scoping study of the urban heat island in bahrain', Landscape and Urban Planning, vol. 113, pp. 47-61.

Senanayake, I, Welivitiya, W \& Nadeeka, P 2013 'Remote sensing based analysis of urban heat islands with vegetation cover in colombo city, sri lanka using landsat-7 etm+ data. Urban Climate', vol. 5, pp. 19-35.

Sobrino, JA Jiménez-Muñoz, JC \& Paolini, L 2004 'Land surface temperature retrieval from landsat tm 5', Remote Sensing of environment, vol. 90, pp. 434-440.

Streutker, DR 2002 'A remote sensing study of the urban heat island of houston, texas', International Journal of Remote Sensing, vol. 23, pp. 2595-2608.

Taha, H 1999 'Modifying a mesoscale meteorological model to better incorporate urban heat 
storage: A bulk-parameterization approach', Journal of Applied Meteorology, vol. 38, pp. 466-473.

Takeuchi, W, Hashim, N \& Thet, KM 2010 'Application of remote sensing and gis for monitoring urban heat island in kuala lumpur metropolitan area. In Map Asia 2010 and the International Symposium and Exhibition on Geoinformation, Kuala Lumpur.

Timmerman, P \& White, R 1997 'Megahydropolis: coastal cities in the context of global environmental change', Global Environmental Change, vol. 7, pp. 205-234.

Treitz, P \& Rogan, J 2004 'Remote sensing for mapping and monitoring land-cover and land-use change-an introduction', Progress in Planning, vol. 61, pp. 269-279.

Voogta, JA \& Oke, TR 2003 'Thermal remote sensing of urban climates', Remote Sensing of Environment', vol. 86, pp. 370-384.

Weng, Q 2001, 'A remote sensing-gis evaluation of urban expansion and its impact on surface temperature in the zhujiang delta, china', International Journal of Remote Sensing, vol. 22, pp. 1999-2014.

Wulder, MA, Franklin, SE, White, JC, Linke, J \& Magnussen, S 2006, 'An accuracy assessment framework for large-area land cover classification products derived from medium-resolution satellite data', International Journal of Remote Sensing, vol. 27, pp. 663-683.

Xiao-Ling, C, Ping-Xiang, L, \& Zhi-Yong, Y 2006, 'Remote sensing image-based analysis of the relationship between urban heat island and land use/cover changes', Remote Sensing of Environment, vol. 104, pp. 133-146.

Xuejie, G, Yong, L, Wantao, L, Zongci, Z \& Giorgi, 2003, 'Simulation of effects of land use change on climate in china by a regional climate model', Advances in Atmospheric Sciences, vol. 20, pp. 583-592.

Zhang, S \& Huang, X 2012, 'Development of virtual campus system based on arcgis', Physics Procedia, vol. 33, pp. 1133-1139. 